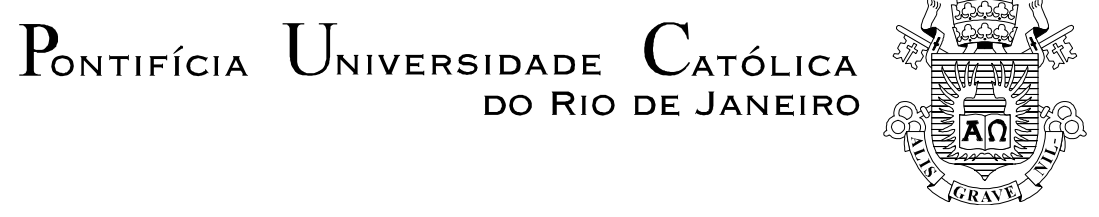

Ana Luiza Saramago Stern

\title{
A Imaginação no Poder - Obediência política e servidão em Espinosa
}

\section{Tese de Doutorado}

Tese apresentada ao Programa de Pós-Graduação em Direito da Pontifícia Universidade Católica do Rio de Janeiro como requisito parcial para obtenção do título de Doutor em Direito.

Orientador: Prof. Adriano Pilatti Co-orientadora: Prof ${ }^{a}$ Marilena de Souza Chaui

Volume I

Rio de Janeiro Janeiro de 2013 
Pontifícia $U_{\text {niversidade }}$ Católica $_{\text {do Rio de Janeiro }}$ $\sqrt{\mathbf{A} \Omega}$

Ana Luiza Saramago Stern

\begin{abstract}
A Imaginação no Poder - Obediência política e servidão em Espinosa
\end{abstract}

Tese apresentada como requisito parcial para obtenção de grau de doutor pelo Programa de PósGraduação em Direito da PUC-Rio. Aprovada pela Comissão Examinadora abaixo assinada.

Prof. Adriano Pilatti
Orientador
Departamento de Direito - PUC-Rio

Profa. Marilena de Souza Chaui

Co-orientadora

USP

Prof. Francisco de Guimaraens Departamento de Direito - PUC-Rio

Prof. Mauricio de Albuquerque Rocha

Departamento de Direito - PUC-Rio

Prof. Luís Antônio Cunha Ribeiro UFF

Prof. Homero Silveira Santiago

USP

Profa. Mônica Herz

Vice-Decana de Pós-Graduação do Centro de Ciências Sociais da PỦC-Rio

Rio de Janeiro, 09 de janeiro de 2013. 
Todos os direitos reservados. É proibida a reprodução total ou parcial do trabalho sem autorização da universidade, do autor e do orientador.

\section{Ana Luiza Saramago Stern}

Graduou-se em Direito na PUC-Rio (2004). Obteve o título de Mestre em Teoria do Estado e Direito Constitucional pela PUCRio (2008). É professora universitária na PUC-Rio, onde atualmente leciona Sociologia do Direito e Metodologia na graduação, e na UNIFESO, onde atualmente leciona Teoria do Estado. Recebeu bolsa CAPES ao longo do Doutorado.

Ficha Catalográfica

Stern, Ana Luiza Saramago

A Imaginação no poder - Obediência política e servidão em Espinosa / Ana Luiza Saramago Stern; orientador: Adriano Pilatti; co-orientadora: Marilena de Souza Chaui - 2013.

2v.; 311fls. ; $30 \mathrm{~cm}$

Tese (doutorado)-Pontifícia Universidade Católica do Rio de Janeiro, Departamento de Direito, 2013.

Inclui bibliografia

1. Direito - Teses. 2. Espinosa. 3. Política. 4. Direito. 5. Obediência. 6. Poder. 7. Estado. I. Pilatti, Adriano. II.Chaui, Marilena de Souza. III. Pontifícia Universidade Católica do Rio de Janeiro. Departamento de Direito. IV. Título. 


\section{Resumo}

Stern, Ana Luiza Saramago; Pilatti, Adriano. A Imaginação no poder Obediência política e servidão em Espinosa. Rio de Janeiro, 2013, 311p. Tese de Doutorado. Departamento de Direito, Pontifícia Universidade Católica do Rio de Janeiro.

Espinosa nos apresenta uma concepção intrinsecamente democrática do poder político, onde a constituição do mais libertário dos regimes ou da mais odiosa das tiranias encontra-se sempre nas mãos da multidão. Neste trabalho, começamos analisando como o filósofo constrói, em sua Ética, uma concepção da imanência absoluta, que o permite recusar qualquer arquétipo de poder transcendente. Em Espinosa, o poder político não se distancia de sua causa imanente, a potência da multidão. $\mathrm{O}$ sujeito político espinosano não se organiza pelo cálculo racional de indivíduos contratantes, mas por uma mecânica afetiva imanente que perpassa o campo social. Estudamos como, próximo da reflexão maquiaveliana, o filósofo se dispõe a analisar a experiência política como campo dos afetos e dos conflitos, e visitamos os principais conceitos e formulações espinosanos acerca da política, enunciados em seu Tratado Teológico-político e seu Tratado Político. Comentamos de que maneira o direito natural é analisado por Espinosa como potência sempre atual e positiva, e o direito civil entendido como expressão imanente das próprias relações constituintes da multidão. Por fim, chegando a nosso tema central, analisamos a obediência política, entendida pelo autor como causa imanente do poder político, e causa, portanto, de seu caráter democrático ou tirânico. Passando pela distinção entre a obediência livre do cidadão e a obediência servil do escravo, estudamos como a imaginação pode engendrar a obediência como desejo de servir e quais afetos, além do medo, podem acompanhar a servidão política.

\section{Palavras chave}

Espinosa; Política;Direito;Obediência;Poder; Estado. 


\section{Résumé}

Stern, Ana Luiza Saramago; Pilatti, Adriano.(conseiller). L'imagination au pouvoir - Obéissance politique et servitude chez Spinoza. Rio de Janeiro, 2013, 311p. Thèse de Doctorat: Departamento de Direito, Pontifícia Universidade Católica do Rio de Janeiro.

Spinoza nous présente une conception intrinsèquement démocratique du pouvoir politique, où la constitutions de le plus libre régime ou la plus odieuses tyrannie sont toujours entre les mains de la multitude. Nous commençons notre travaile pour l'etude de l'Èthique, et de la une conception spinoziste de l'immanence absolue, qui interdisent tout archétype d'une pouvoir transcendante. Pour Spinoza la puissance de la multitude est la cause immanente de le pouvoir politique. Le sujet poitique multitude n'est pas organisé par le calcul rationnel d'un contract entre les individus, mais par une mécanique affective immanente qui imprègne le domaine social. Nous étudions comment le philosophe afirme l'expérience politique comme un champ d'affects et de conflits, et nous visitons les principaux concepts et formules spinozistes sur la politique, énoncée dans son Traité Théologique-Politique et son Traité Politique. Nous analysont de quelle façon la loi naturelle est afirmée par Espinosa comme expression de la puissance positive et actuelle de la multitude et la loi civile perçue comme une expression immanente des propres relations constitutives de la multitude. Enfin, à notre thème central, nous analysons l'obéissance politique comprise par l'auteur comme cause immanent du pouvoir politique et par conséquent cause de son caractère démocratique ou tyrannique. En passant par la distinction entre l'obéissance libre des citoyens et l'obéissance servile de l'esclave, nous étudions comment l'imagination peut engendrer l'obéissance comme désir de servir, et les affects que, au-delà de la peur, peut accompagner la servitude politique.

\section{Mot-Clefs}

Spinoza ; Politique ; Droit ; Obéissance ; Pouvoir ;Etat. 
"Para que não mais existam amores servis"

Maiakóvski 


\section{Agradecimentos}

"O agradecimento ou a gratidão é o desejo ou o empenho de amor pelo qual nos esforçamos por fazer bem a quem, com igual afeto de amor, nos fez bem."

Espinosa

Em quatro anos de doutorado não se escreve apenas uma tese, é a vida que se desenrola, é o tempo que escreve em seu ritmo, ora mais lento ora mais rápido, às vezes avassalador, eventos alegres e tristes, bons e maus encontros, tropeços e sorrisos. Muito trabalho, muito crescimento e um caminho que eu jamais poderia ter trilhado sozinha. Se aqui estamos, chegamos com a inestimável ajuda de muitos. Ainda que impossível lista-los todos, segue os agradecimentos àqueles que, mais próximos, contribuíram com orientação e incentivo, com palavras de conforto ou mesmo merecidas palavras duras, com um abraço ou apenas com um olhar doce entre a escuridão, com tudo que tece as vidas nos laços da amizade.

Ao prof. Adriano Pilatti pela orientação que, muito além dessa pesquisa, norteia, desde minha graduação, minha formação acadêmica e profissional. Minha mais sincera gratidão pela sua generosidade e incentivo, pela justa medida entre amizade e orientação, e pela ética e liberdade que só se ensinam pelo exemplo.

Ao prof. Francisco de Guimaraens pela amizade no pensamento, pelas obras que são fonte de e abriram o caminho para esta pesquisa, e pela amizade, generosidade e incentivo sem os quais esta obra dificilmente teria se realizado desta forma..

Ao prof. Maurício Rocha, por me apresentar adequadamente ao pensamento de Espinosa e pelos anos de estudo no seu Círculo de leitura Spinoza \& a filosofia (e lá se vão já doze anos), cujos aprendizados são gênese constituinte desta pesquisa. Pela amizade, generosidade e incentivo. 
À profa. Marilena Chaui minha especial gratidão pela orientação deste trabalho, a leitura atenciosa e as observações e sugestões sempre muito generosas. Eu que já me sentia sua aluna antes de conhecê-la, pela leitura de suas obras, tive a imensa alegria de, conhecendo-a pessoalmente, ver como a virtù pode ser simples e ao mesmo tempo grandiosa.

Aos professores Homero Santiago e Luis Antonio Ribeiro pela participação na banca de avaliação deste trabalho, pelo debate profícuo e generosidade de ideias naquela ocasião.

Aos professores do Departamento de Direito da PUC-Rio, pelos ensinamentos na Graduação e Pós-Graduação e pela generosa acolhida profissional. Por todos, meus agradecimentos especiais à profa. Regina Coeli Soares pelas conversas que me ensinam muito sobre esse ofício que é o nosso.

Aos funcionários do Departamento de Direito da PUC-Rio, pela eficiência, presteza e bom humor com que sempre me atenderam, seja como aluna seja como professora.

Aos colegas de doutorado João Carlos Castelar, José Guilherme Bergman e Daniel de Oliveira pela divertida convivência e a Thula Rafaela Pires pela amizade.

Ao Grupo de Estudos Espinosanos da USP pela generosa acolhida e ricos e producentes debates, por todos, especialmente a Ericka Marie Itokazu pela amizade que ignora distâncias geográficas.

À PUC-Rio pelo ambiente aberto ao debate e o clima de amizade, e por acolher-me como aluna e professora em sua atmosfera de liberdade imprescindível ao pensamento.

À CAPES pela colaboração nas condições materiais essenciais para o desenvolvimento desta pesquisa.

Aos amigos que iluminam com alegria e esperança a escuridão, compartilham com abraços as conquistas, nunca me deixam desistir e fazem da jornada de cada dia, seja ela pesada ou leve, este maravilhoso caminho chamado vida. Em nome de todos, os mais próximos: Renato, Anderson Brandão e Jorge Eduardo Lucas Costa. E ainda: Bruna Soalheiros e Beatriz Lima pelos anos de amizade. 
Ao meu pai pelo amor e apoio material. Aos meus avós maternos Maria Cecília e Eldyr Saramago, meu irmão Luis Felipe e minha mãe Carmen pelo amor e imprescindível apoio no essencial, pelo suporte nas piores horas e por acreditarem e me ensinarem que depois de uma queda é sempre tempo de levantar e seguir em frente. 


\section{Sumário}

$\begin{array}{ll}\text { Introdução } & 12\end{array}$

1. A imanência absoluta 22

1.1. O plano de imanência 22

1.2 Expressões singulares 33

$\begin{array}{ll}1.3 \text { Conatus } & 48\end{array}$

2 Soberania. $\quad 56$

2.1 Superstição e servidão 56

$\begin{array}{ll}2.2 \text { O sistema do medo. } & 73\end{array}$

$2.3 \mathrm{O}$ medo e a alegria: Hobbes e Espinosa 89

2.3.1 A recusa do fundamento teológico do poder político 90

2.3.2 A causalidade eficiente transitiva $x$ causalidade eficiente imanente

2.3.3 Conatus e concepção antropológica 94

$\begin{array}{ll}\text { 2.3.4 Liberdade } & 103\end{array}$

2.3.5 A constituição do campo político 105

2.3.5.1 Estado de natureza 106

2.3.5.2 Pacto social e o Leviatã 110

2.3.5.3 Direito natural e direito civil 113

3 A constituição do campo político 117

3.1 A multidão como sujeito político 117

3.1.1 Indivíduo e subjetividade 118

3.1.2 Variações e transformações $\quad 124$

3.1.3 Imitação afetiva e a gênese constituinte da multidão 131

3.1.4 A multidão como multiplicidade de singularidades 145

3.2 Imperium: a potência da multidão 156

3.2.1 A democracia intrínseca ao campo político 156 
3.2.2 Experiência política e o agudíssimo Maquiavel

3.2.3 Imperium e instituições

3.3.3.1 A monarquia espinosana

3.2.3.2 A aristocracia espinosana

3.3 O campo jurídico: direito natural e direito civil 202

3.3.1 Direito natural 203

3.3.2 Estado de natureza 211

$\begin{array}{ll}\text { 3.3.3 Direito civil } & 217\end{array}$

4 A imaginação no poder - obediência política e servidão 225

4.1 O ingenium da multidão: o comum nas mentes e nos corpos 226

4.2 O cidadão e o escravo 236

4.3 Obediência e desejo de servir 245

4.4 Reinar sobre os ânimos 256

4.5 A multidão servil 264

4.5.1 O amor ao tirano 265

4.5.2 Do um ao outro, da semelhança ao ódio 270

4.5.3 Muitos meios de dominação 278

4.5.4 A servidão sem tirano 287

5 Conclusão 293

6 Bibliografia 304 